\title{
Application and study on the reclamation area of aquatic eco-situ remediation technology
}

\author{
Kaiping $X u^{1, a}$ \\ ${ }^{1}$ Zhejiang Institute of Hydraulics \& Estuary, China \\ axukaiping051@163.com
}

\begin{abstract}
Keywords: aquatic eco-situ remediation technology, ecological floating bed, artificial aquatic mat, submerged plant, purification effect, influencing factors

Abstract. Study on purification effect of different water eco-situ remediation technology on the reclamation area. The results showed that the optimal water quality purification effect was $3 \#$ test zone (ecological floating bed+ artificial aquatic mat) and 6\# test zone (ecological floating bed + submerged plant), which could be used in the Zhejiang reclamation area of eutrophication water. The saline-alkali, water temperature and atmospheric oxygen was the main influencing factor on the test area.
\end{abstract}

\section{Introduction}

Aquatic eco-situ remediation technology is a new type of environmental biotechnology developed in recent years, which was widely used in lakes, reservoirs, rivers, ponds and other freshwater areas. It become the fundamental way and the development trend of controlling the eutrophication ${ }^{[1]}$. With the constraints of land resource, reclamation area in Zhejiang has expanded every year, aggravating the problem of rivers and lakes pollution, as the impact the salt tide, the water salinity and $\mathrm{pH}$ values are slightly higher, and the coastal environment is vulnerable to waves, commonly used water ecological restoration in situ technology can not adapt to the water environment in the reclamation area. Many early studies found that had used techniques of ecological floating bed, artificial aquatic mat, submerged plant alone having good purification effect, but there were system instability, poor visual effects and other drawbacks. Therefore, in this paper the above three types of aquatic eco-situ remediation technology were combination arranged ${ }^{[2]}$, and a reclamation area was chosen as test zone, aquatic preferably suitable for reclamation area was selected, the dynamic changes of water quality was monitored, plant growth conditions was observed, and the water quality purification effect was compared.

\section{Materials and methods}

Test area. Test area is located in Hangzhou Xiaoshan Linjiang Industrial Park, covering 14.4 acres, is a rectangular pond with about $170 \mathrm{~m}$ in length, $60 \mathrm{~m}$ in width. Test area was reclaimed land in the early 1950s, was supported for the South American shrimp ponds before construction, the water source for the test area was from the tidal reach in the eastern side (water quality inferior $\mathrm{V}$ class in long-term, salinity generally about 1\%o), mostly surrounding farmland, livestock breeding and planting seedlings, and no methods were taken to interception nanotube scattered farmers.

Test scheme. The test water area was divided into six independent zones, each water area district of about $55 \mathrm{~m} * 30 \mathrm{~m}$, maximum depth control in about $2.5 \mathrm{~m}$. Different ecological restoration methods were arranged in each text zone: $1 \#$ (no.1 test zone) blank, 2\# submerged plants, 3\# ecological floating bed+ artificial aquatic mat, 4\# artificial aquatic mat, 5\# ecological floating bed, 6\# ecological floating bed+ submerged plants.

The ecological floating bed covered an area of $384 \mathrm{~m}^{2}(24 \mathrm{~m} * 16 \mathrm{~m})$, was about $25 \%$ of the water area, plants are mainly bamboo reed, lythrum salicaria, calamus, nymphoides peltatum and gather grass; The new fiber artificial aquatic mat hanging in the ecological floating bed below, each district hung quantity is $80 \mathrm{~kg}$; Submerged plants was mainly hornwort. 
Water is filled and drained regularly to simulate the natural water habitat, 3 times of obvious water filling and drainage in total is performed in one year of testing.

monitoring content. Before the operation of testing ecological methods, the original values of each zone is monitored three times; After the operation of ecological methods (May, 2013 to March 2014) sampling frequency is 2-3 times a month during April to September, and the other time is one time a month during. The main indicators monitored and analysis methods are shown in Table 1.

Table 1. Water quality index and analysis method

\begin{tabular}{|c|c|c|c|}
\hline Indicator & Analysis method & Indicator & Analysis method \\
\hline $\mathrm{TN}$ & TOC instrument & TP & spectrophotometry \\
\hline $\mathrm{NH}_{3}-\mathrm{N}$ & spectrophotometry & chlorophyll-a & spectrophotometry \\
\hline $\mathrm{DO}$ & HACH sension6 DO portable analyzer & salinity & SD150 multi-parameter instrument \\
\hline $\mathrm{pH}$ & HACH sension1 $\mathrm{pH}$ portable analyzer & & \\
\hline
\end{tabular}

removal rate $(\%)=(\mathrm{C} 0-\mathrm{Ci}) / \mathrm{C} 0 * 100 \%$, where $\mathrm{C} 0$ is the water quality index of initial concentration, $\mathrm{Ci}$ concentration of water quality index in some day.

\section{Results and analysis}

Analysis of dynamics water quality concentration. According to the time of water filling and drainage in test zone, dynamic monitoring could be divided into three phases in each zone: Stage I was before and after the arrangement of the ecological measures; Stage II was the initial operation of ecological measures; Stage III was the stable operation of ecological measures. The concentration indicators of nitrogen, phosphorus, chlorophyll-a were dynamically analyzed in each phase.

Stage I: Fig. 1 shows the water quality indicators monitored before the arrangement of ecological restoration measures, at March 29th, April 7th and 17th respectively. The nutrient indicators were relatively stable except the chlorophyll-a. The first water quality monitoring in the test area after the arrangement of ecological restoration measures and water filling was carried out at May 10th. The nutrient indicators of $\mathrm{TN} 、 \mathrm{NH}_{3}-\mathrm{N}$ and $\mathrm{TP}$ decreased obviously when compared with river after the running the measures. The concentration of chlorophyll-a in the river could be 360 times of that in the test area, but first decreased and then increased trend of the concentration in the test area. The concentration of $\mathrm{NH}_{3}-\mathrm{N}$ in the test area decreased obviously after one week.

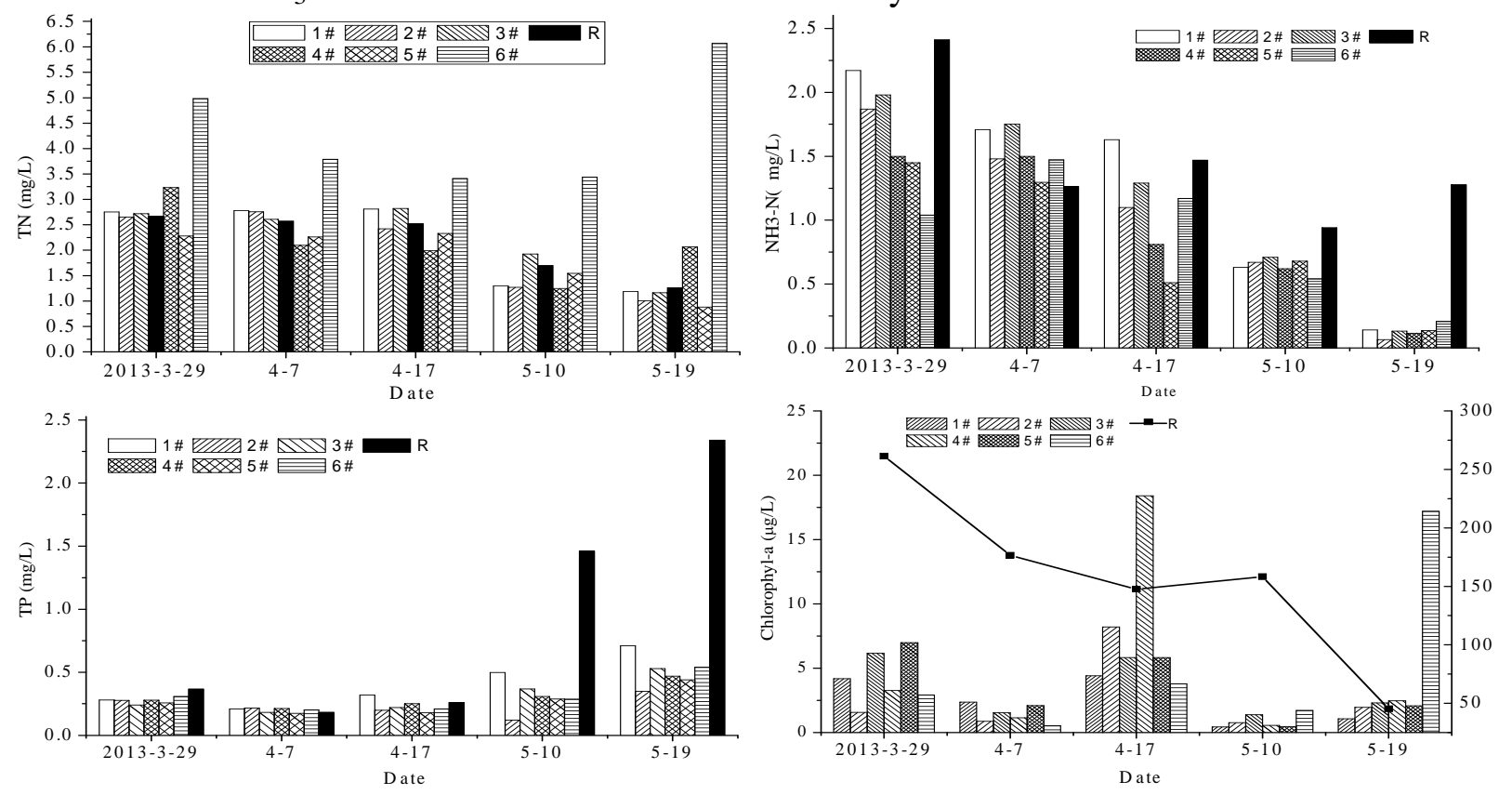

Fig. 1 dynamics water quality concentration of Stage I

Stage II: At the beginning of operation, the plants of aquatic eco-situ remediation measures were in the stage of growth and reproduction. As the temperature increasing and the heavy rainfall, the concentrations of $\mathrm{NH}_{3}-\mathrm{N}$ in the river and test zone were all less than $1 \mathrm{mg} / \mathrm{L}$ that changed slightly, 
while the other concentration in the test zones were in an unstable state. The concentrations of TN and TP decreased after July, while the chlorophyll-a increased especially in the 1\# and 2\# test zones, the concentrations were higher than that in the river. Spirogyra algae etc. appeared in the $1 \#$ and $2 \#$ test zones when water clarity, color and other sense evaluation were poor, but was better than river.
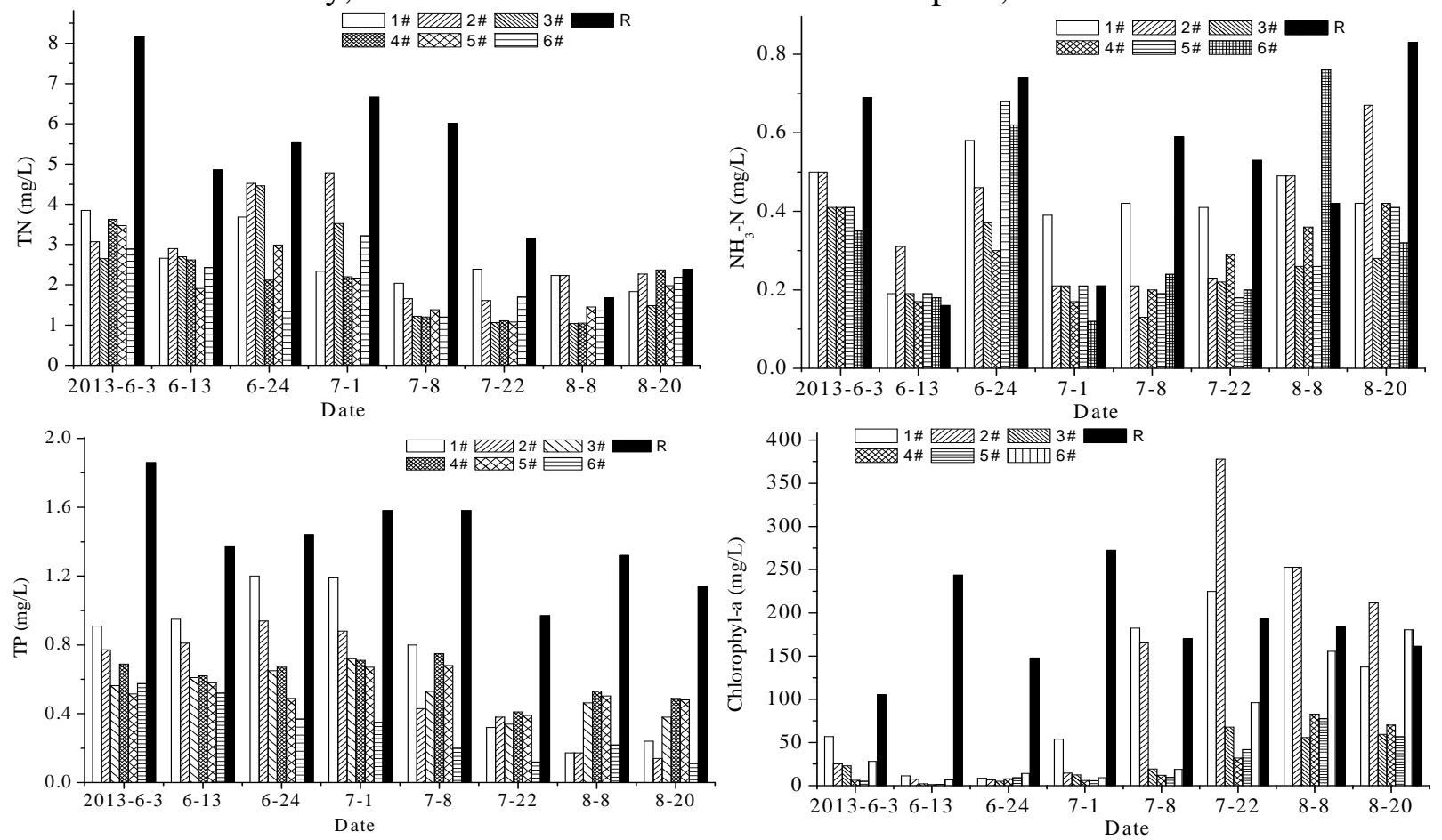

Fig. 2 dynamics water quality concentration of Stage II
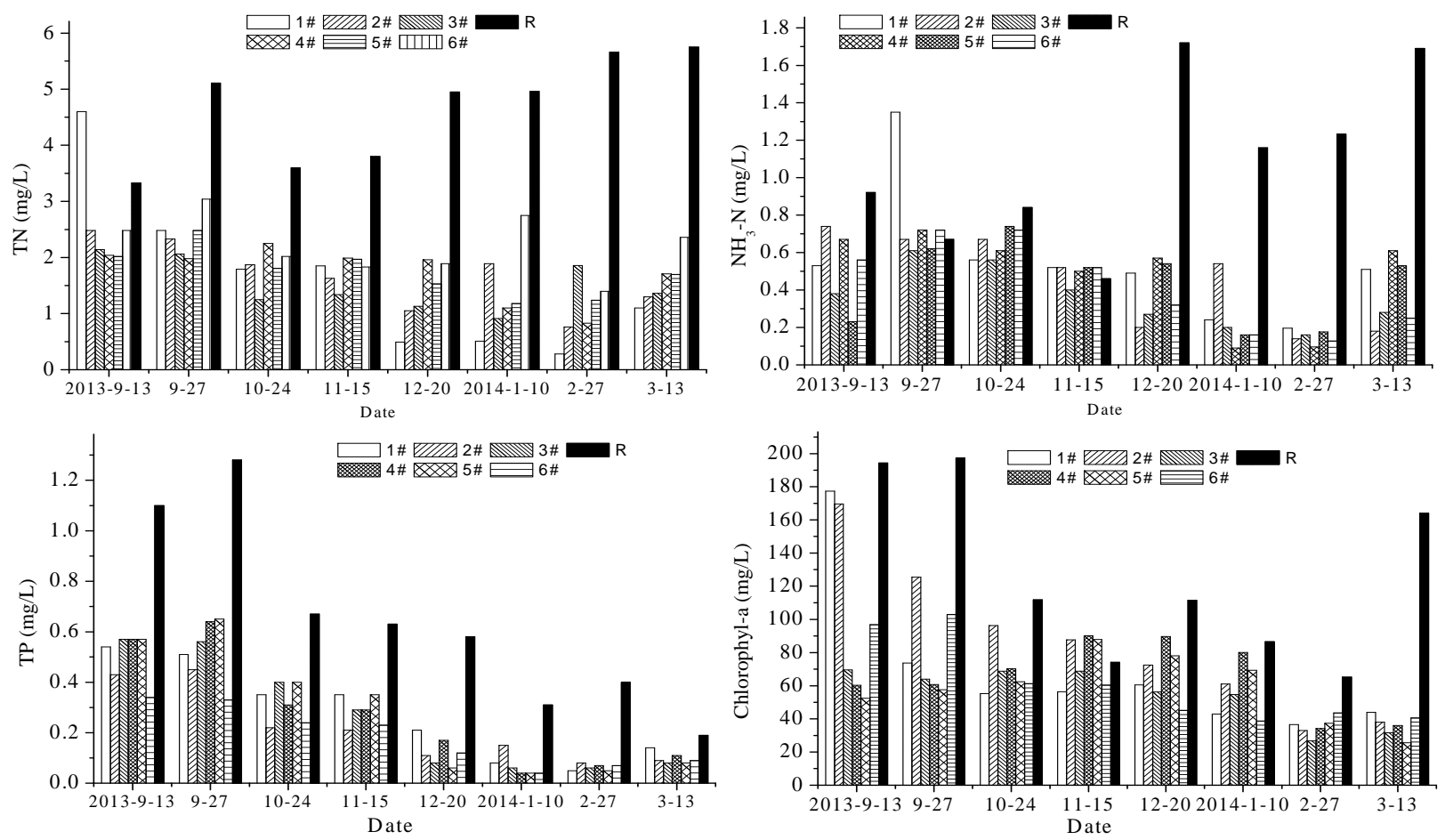

Fig. 3 dynamics water quality concentration of Stage III

Stage III: Extreme weather reduced after September, the ecological measures also entered the stable operation stage. The adaptable and tolerant capacity of plants increased. The indicators in all the test zones decreased during September to December in general, reached the lowest value at December, obviously better than that in the river. Water quality in the test zone was better and stable 
in the winter, when the temperature increased with the Spring season coming in the next year, eutrophication material in the water increased slightly but generally stable.

Analysis on water quality purifying effect. when the stable operation of ecological measures (Stage III), this study made an analysis on removal rate of eutrophication each test zone. The test zone of ecological measures were better than blank test zone about eutrophication control index. Fig. 4 shows each index had good reduction effect of eutrophication: reduction rate of TP is up to about $90 \%$, which $3 \#$ test zone is highest; reduction rate of chlorophyll-a is up to about $70 \%-80 \%$, which $5 \#$ test zone is highest; reduction rate of TN is up to about $30 \%-60 \%$, each zone had large differences, which1\# test zone is lowest and $3 \#$ test zone is highest; reduction rate of $\mathrm{NH}_{3}-\mathrm{N}$ in $2 \#$, $3 \#$ and $6 \#$ test zone is higher than in the others. $3 \#$ and $6 \#$ test zone had good diaphaneity and low colority from sense evaluation that water quality better than other test zone and water source.

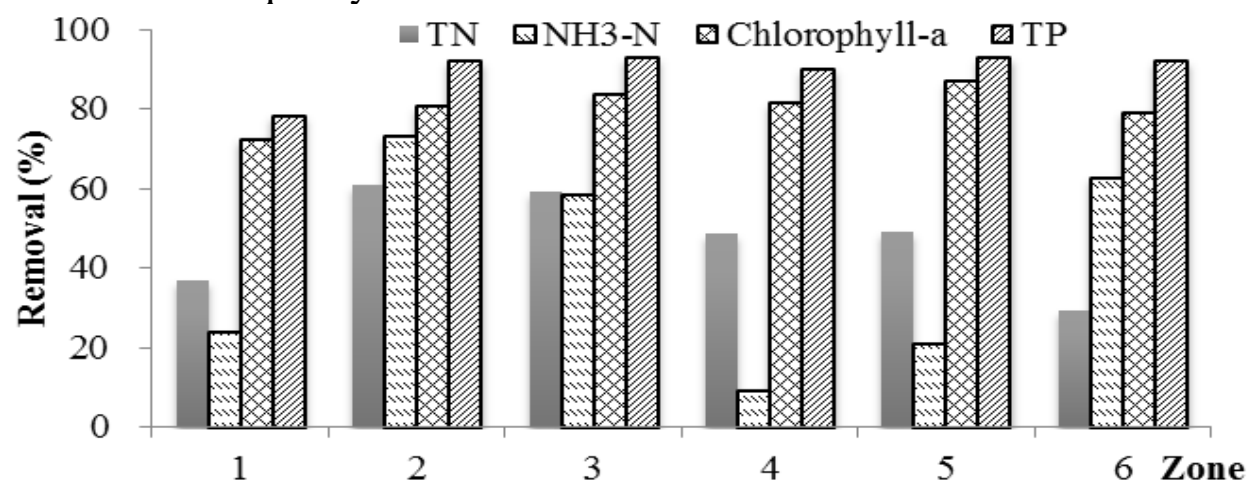

Fig. 4 Removal rate of eutrophication each test zone

\section{Discussion}

The eutrophication control measures of the main influencing factors are discussed, including saline-alkali, water temperature and atmospheric oxygen.

Saline-alkali. Water source of test zone is the surrounding river that $\mathrm{pH}$ and salinity kept in 8 and $1.5 \%$. Research shows that when $\mathrm{pH}$ was too high and the velocity of the water was slow, inorganic nitrogen in water exists mainly as $\mathrm{NH}_{3}-\mathrm{N}^{[3]}$. Very low nitrate content did not even reach the detection limit in Stage I, so we only monitored concentration of $\mathrm{TN}$ and $\mathrm{NH}_{3}-\mathrm{N}$. The river completely accords with the law that salinity level had close relationship with rainfall, evaporation and seasonal changes $^{[4]}$, but the test zone was not similar. Saline-alkali level of the zone is $9(\mathrm{pH})$ and 1.5-2.0\% (salinity) that was mainly affected by groundwater. The review indicate that the nitrification-denitrification effect was the strongest with $\mathrm{pH}$ 8. But too high salinity and $\mathrm{pH}$ would affect the $\mathrm{NH}_{3}-\mathrm{N}$ removal rate, resulting in stunted growth of aquatic plants in general, and it has inhibitory effect on microorganism ${ }^{[5]}$. $4 \#$ test zone used technology of artificial aquatic mat alone that the microbial enrichment effect was not ideal. Bamboo reed, lythrum salicaria, calamus, nymphoides peltatum and gather grass on the ecological floating bed had salt-tolerance ability, at the same time to control water eutrophication. So the combination structure of the ecological floating bed and artificial aquatic mat is best.

Water temperature. The water temperature effect was mainly reflected in the aquatic life activity. Degradation of organic matter is generally the most suitable temperature is 15 to 30 degrees Celsius ${ }^{[6]}$. Aquatic plants were significantly affected by water temperature, but bamboo reed and lythrum salicaria had resistance to low and high temperature. Besides artificial aquatic mat was little affected by water temperature. Because of the blue-green algae like high temperature, so the chlorophyll-a showed better removal rate after september.

Atmospheric oxygen. The test zone is located in the reclamation area, characteristics of wind throughout the year especially in winter. Related literature shows that air flow intensity is larger and positively related to the effect of dissolved oxygen content of the surface layer ${ }^{[7]}$. Due to shallow water depth and strong wind, it was natural aeration mode without additional artificial oxygen. 


\section{Conclusions}

Water quality of all the test zone is better than the river, which is continued at a low level in winter. Each zone of ecological measures is all better than the blank test. The optimal water quality purification effect was $3 \#$ test zone (ecological floating bed+ artificial aquatic mat) and 6\# test zone (ecological floating bed + submerged plant), which formed the stereo ecosystem and can be used in the Zhejiang reclamation area of eutrophication water. The saline-alkali, water temperature and atmospheric oxygen is the main influencing factor on the test area.

\section{Acknowledgements}

This work was financially supported by the National Science and Technology Major Project (2014ZX07101-011) and Zhejiang water conservancy science and technology plan projects (RB 1405 ).

\section{References}

[1] M.A. Burford, K. Lorenzen. Modeling nitrogen dynamics in intensive shrimp ponds: the role of sediment remineralization [J]. Aquaculture, 2004, 229(1):129-145.

[2] S. Nakamura. "Design with Nature" in nature-oriented river works in Japan[R]. Int.WS for Eco-hydraulics \& Eco-rivers Engineering, Taiwan, 2003.

[3] Z. Jun, G. Feng, et al. Study on temporal and eutrophication in the spatial distribution of nutrients and seawater of Jiaozhou Bay wetland [J]. Progress in fishery sciences, 2011, 32(6):107-114.

[4] W. Wei, S.N. Li, et al. Physiological Response of Wetland Vegetation in Salt Stress Environment [J]. Forest resources management, 2015, 4(2):125-129.

[5] H. Wang, Z.W. Shang, et al. Holocene shoreline changes and marine impacts on the muddy coast, western Bohai Bay [J]. Geological Bulletin of China, 2010, 29(5):627-640.

[6] Burford MA, Lorenzen K. Modeling nitrogen dynamics in intensive shrimp ponds: the role of sediment remineralization [J]. Aquaculture,2004,229(1):129-145.

[7] Nakamura S. "Design with Nature" in nature-oriented river works in Japan[R]. Int.WS for Eco-hydraulics \& Eco-rivers Engineering, Taiwan, 2003. 